\title{
O gosto pelo real no teatro contemporâneo
}

\section{Resumo}

A emergência de novas práticas e reflexões teatrais nas últimas décadas, muitas delas relacionadas à utilização de documentos em cena e à recusa da ficção, da mimese e de outros marcadores do teatro dramático, exige a análise das condições históricas gerais que permitem ou potencializam o surgimento destes fenômenos.

Palavras-chave: Documento em cena; Ficção teatral ; Teatro contemporâneo.

\section{Abstract}

The emergence of new practices and new theatrical reflections in recent decades, many of them related to the use of documents on the scene and the refusal of fiction, mimesis and other markers of dramatic theater requires the examination of the general historical conditions that enable or empower these phenomena.

Keywords: Contemporary theater; Document on stage; Theatrical fiction.

\section{0 teatro e a história}

A análise da produção tardia do teatro moderno no Brasil só pode ser feita à luz da modernização do país. Este é o procedimento analítico adotado por Iná Camargo Costa (1998, p. 11-50) quando leva em conta, entre outros aspectos, o contexto do imediato segundo pós-guerra, o fim da ditadura Vargas, o surgimento de um novo modelo de desenvolvimento econômico, a mudança no perfil da burguesia nacional, o aumento do consumo interno. Ou seja, a compreensão da "transição para o épico" (é disso que a autora trata), passa pela compreensão das condições gerais que permitiram ou produziram essa transição. Por este motivo "deveriam ser óbvias" (COSTA, 1998, p.17) as razões que fizeram da União Soviética o primeiro país a desenvolver formas mais acabadas de teatro épico. Da mesma forma, deveriam ser óbvias as razões pelas quais o teatro épico não se desenvolveu com a mesma intensidade na

\footnotetext{
1 Diretor e pesquisador teatral. Doutor em Teatro pela Universidade Sorbonne Nouvelle, Paris 3 e Universidade
} de São Paulo (USP). E-mail para contato: fkinas@usp.br. 
França: faltava ali o fermento social que agitava a União Soviética e a Alemanha, também berço de importantes experiências com o teatro épico (Piscator e Brecht).

Trata-se de reconhecer e analisar a conexão profunda entre a realidade de um país (o estágio das suas forças produtivas, suas relações de produção, sua dinâmica social) e suas realizações no âmbito cultural e artístico. É esta a ambição de Walter Benjamin ao analisar as transformações da arte nas primeiras décadas do século 20 a partir das novas técnicas de reprodução: "Tendo em vista que a superestrutura se modifica mais lentamente que a base econômica, as mudanças ocorridas nas condições de produção precisaram mais de meio século para refletir-se em todos os setores da cultura" (BENJAMIN, 1985, p.165).

Assim como não se pode negar a conexão entre a formação do indivíduo burguês e o nascimento do drama burguês, ou entre a ascensão do proletariado alemão e o teatro épico germânico (basta pensar nos milhares de sócios que sustentavam o Volksbühne), não se pode ignorar as relações umbilicais entre o capitalismo contemporâneo (espetacular, cognitivo, globalizado, financeirizado etc.) e o teatro feito hoje em dia.

Não se trata, evidentemente, de repetir esquematismos que resumem complexos processos sociais a um quebra-cabeça de poucas peças. A compreensão de fenômenos culturais não deve prescindir de apuradas análises históricas, mas não pode se contentar com regras prontas, sejam elas provenientes do marxismo ou de qualquer outra matriz de pensamento. ${ }^{2}$ Não é razoável ignorar disputas reais que agitam as sociedades (sempre relacionadas ao contexto internacional) e que incidem sobre suas formas de produção cultural. É por isso que Iná Camargo Costa se dispõe a "alertar para os obstáculos que se colocam à compreensão da atividade teatral em país de periferia, condenado à importação das últimas manifestações da moda sem maiores cuidados com as diferenças de fuso horário" (COSTA, 1998, p.9).

Assim como Brecht insistiu na filiação do teatro moderno à "era científica"s, é preciso insistir no desvelamento das relações que se estabelecem entre o teatro contemporâneo e o contexto histórico do qual faz parte. No entanto, o próprio Brecht fez observações esclarecedoras sobre como abordar as determinações sociais do teatro:

Nós precisamos de um teatro que não permita somente as sensações, os esboços e os impulsos que autoriza cada vez o campo histórico das relações humanas sobre o qual as diversas ações se desenrolam, mas que

\footnotetext{
2 "O marxismo aguça o senso de realidade de alguns, e embota o de outros". Roberto Schwarz, "Valor intelectual", in Crítica à razão dualista, O ornitorrinco. São Paulo, Boitempo, 2008, p. 23.

3 Cf. por exemplo, Bertolt Brecht, "Petit organon pour le théâtre", in Ecrits sur le théâtre 2, Paris, Arche, 1979, p. 9-45.
} 
empregue e engendre as ideias e os sentimentos que desempenham um papel na transformação do próprio campo [...].

As condições históricas não devem certamente ser concebidas (nem serão construídas) como poderes obscuros (os segundos planos), elas são, ao contrário, criadas e mantidas pelos homens (e serão modificadas por eles): tudo o que é colocado então em ação é o que as constitui. (BRECHT, 1979, p.24-25).

A leitura atenta desses trechos não justifica a suposição de que em Brecht o pensamento seja mecânico e dogmático. Está claro para ele a existência de um fluxo de duas mãos entre o fenômeno teatral e o "campo histórico das relações humanas."Vão no mesmo sentido as afirmações de Peter Bürger sobre o desenvolvimento (emancipação) da arte em relação aos desenvolvimentos tecnológicos, tal como analisado por Walter Benjamin:

Ora, a emancipação é um processo que pode ser efetivamente promovido por meio do desenvolvimento das forças produtivas, na medida em que estas preparam um campo de novas possibilidades disponíveis para a concretização de necessidades humanas, mas isso não pode ser pensado independentemente da consciência humana. Uma emancipação que se impusesse natural e espontaneamente seria o contrário da emancipação (BÜRGER, 2008, p.70).

Bürger mostra que a transposição do esquema marxista que relaciona o desenvolvimento das forças produtivas com a alteração substancial das relações de produção não pode ser aplicada mecanicamente à relação entre arte e sociedade. Não basta que haja alteração de situação social (como o desenvolvimento de novas técnicas de reprodução), para que a situação artística (o sistema de arte e as obras ou processos) sejam automaticamente alterados. O "desenvolvimento técnico não deve ser interpretado como variável independente, sendo ele próprio dependente do desenvolvimento do todo social", diz Bürger, acrescentando que "não se deve atribuir unicamente ao desenvolvimento dos procedimentos técnicos de reprodução a ruptura decisiva no desenvolvimento da arte na sociedade burguesa" (BÜRGER, 2008, p.74). Seria necessário levar em conta tanto uma relativa autonomia da vontade humana (que estaria em ação), como a nova divisão do trabalho que se estabelecia neste tipo de sociedade, responsável pela especialização generalizada das ocupações, incluindo as artísticas.

Efeitos específicos, como a atrofia da função mimética na pintura, que pode ser explicada pelo surgimento da fotografia, não podem ser generalizados para outros subsistemas artísticos, como a literatura. Nem mesmo o surgimento e a generalização do mercado podem ser vistos como causas únicas na reconfiguração das artes. "O processo contraditório do surgimento da esfera social que designamos como arte, que (sempre pressionado por movimentos contrários) por séculos se prolongou, não pode ser deduzido de uma só 'causa', ainda que seja de tão central importância para o todo social como o mecanismo de mercado" (BÜRGER, 2008, p. 87). 
É útil à discussão a ideia de que as vanguardas históricas tentaram "direcionar a experiência estética (que se opõe à práxis vital), tal como o esteticismo a desenvolveu, para a vida cotidiana" (BÜRGER, 2008, p. 77). Associando as análises de Szondi e Bürger é possível esboçar um quadro mostrando que manifestações de parte do teatro contemporâneo expressam, de fato, uma transição para a "vida cotidiana" (exemplificada pela recusa, ou questionamento, do regime ficcional clássico e pela farta e plural utilização do documento em cena, o que mais adiante será discutido como "gosto pelo real"), e que este movimento não se confunde com a epicização tal como descrita por Szondi em Teoria do drama moderno (2003). Esta transição, em muitos casos, tem como objetivo reagir à ordem existente, ao status quo. Uma parte do teatro contemporâneo, que opera esta transição para a "vida cotidiana", estaria, no entanto, sujeita às permanências do velho modelo e, portanto, mais receptiva à aceitação da ordem existente, embora ambas flertem com a desestabilização dos marcadores clássicos do teatro (ficção, mimese, personagem, conflito).

É importante notar que determinadas críticas feitas à Bürger, como a que pretende que ele esteja "cego à arte ambiciosa do seu tempo" (FOSTER, 2001, p.16), só fazem sentido no contexto pós-estruturalista. Hal Foster vê evolucionismo primário e determinismo nas posições de Bürger, comparando-o com o crítico de arte conservador Clement Greenberg. Se a intenção é, de fato, "melhorar" a tese "demasiado influente" de Bürger, Foster deveria avaliar sua complexidade. O próprio Bürger reconheceu falhas na formulação original, publicada em 1974, mas elas estão longe de confirmar a hipótese de Foster segundo a qual o crítico alemão estaria tentando aplicar mecanicamente a ideia de Marx sobre a "repetição da história como farsa" às relações entre vanguardas históricas e neovanguardas. Se é miopia não perceber a importância das neovanguardas no panorama artístico e social da segunda metade do século 20 , também é miopia não perceber que elas tiveram um papel considerável no processo de institucionalização da rebeldia e da crítica artísticas. Portanto, parece claro que há, de fato, algo de inautêntico no gesto destas vanguardas contemporâneas, como afirma Bürger. Isto não invalida seus projetos estéticos e políticos, mas indica algumas de suas limitações. Avaliação semelhante pode ser aplicada no estudo de práticas cênicas contemporâneas que vestem o figurino da ousadia conveniente à ordem dos negócios culturais.

Um mérito inegável na obra de Bürger consiste em vincular processos artísticos a condições sociais e históricas gerais. Esse ponto parece incomodar Foster. Para 
ele, Bürger condena todas as vanguardas ao fracasso, "com a única exceção dos movimentos que estão no meio de revoluções" (FOSTER, 2001, p.17). Diferente da avaliação de Foster, essa ideia de Bürger parece acertada, antes, vale o reparo de que, mesmo em meio à revoluções, as vanguardas também podem fracassar. E vejam que Foster não é insensível às conexões entre arte e processos histórico-sociais:

A partir da revolução industrial, existe uma contradição entre a base de destreza da arte visual e a ordem industrial da vida social [...] A este respeito, também, a serialidade do minimalismo e o pop é indicativa da produção e do consumo no capitalismo avançado, pois ambos registram a penetração dos modos industriais em esferas (a arte, o ócio, o esporte) que em outro momento estiveram afastados deles. (FOSTER, 2001, p.67).

Tratando de outro período histórico, Jean-Pierre Sarrazac reforça o acerto do método sócio-estético de análise. Ele demonstra que o apreço dos frequentadores do teatro clássico francês pelo distanciamento (estamos no século 17, não se trata, portanto, do distanciamento brechtiano) só pode ser compreendido à luz "de um modo de vida e de uma concepção de mundo" (SARRAZAC, 2002, p.77) específicos. Em sua análise, Sarrazac recorre à Thomas Pavel, que identifica na tradição cristã e na herança do classicismo as bases materiais desta atitude estética.

\section{O teatro e o real}

Uma parte do teatro contemporâneo iniciou a autocrítica radical das produções teatrais e dos próprios códigos teatrais. ${ }^{4}$ Mantendo parentesco com aquilo que fizeram as vanguardas históricas, especialmente o dadaísmo, parte do teatro contemporâneo passou a recusar as formas artísticas hegemônicas e, simultaneamente, a colocar em questão os fundamentos do teatro. Uma das consequências deste movimento, embora não a única, foi a rejeição da idealização burguesa da arte, responsável pelo conceito de "autonomia". Junto veio a reivindicação do "real", do "documental," e sua contrapartida, a recusa da "ficção" e da "mimese". Recusa-se o que aparece como falsificação esteticizante da vida. Este teatro rejeita o consolo e o apaziguamento que a ficção engendraria, independentemente dos conteúdos veiculados.

4 O termo "autocrítica" é proposto em oposição à "crítica imanente", com o mesmo sentido que Ihe dá Peter Bürger: "Exemplos de crítica imanente ao sistema seriam, digamos, a crítica dos teóricos do classicismo francês ao drama barroco, ou a de Lessing às imitações alemãs da tragédia clássica francesa. A crítica funciona, aqui, dentro da instituição do teatro. Nela se defrontam, umas contra as outras, várias concepções da tragédia, as quais (passando por múltiplas mediações) se fundamentam em posições sociais. Dela cumpre distinguir um outro tipo de crítica, que atinge a instituição arte como um todo: a autocrítica da arte". (BÜRGER, 2008, p.56-57). 
Da mesma forma que os objets trouvés/ready mades de Duchamp não representam ou não deveriam representar uma realidade exterior a eles, parte do teatro parece exercitar com atraso, mas de forma contundente e sob as condições históricas atuais, este caminho de crítica à reprodução e à representação (ou imitação). É um movimento que expressa o gosto e o desejo pelo real, traduzido em múltiplas formas: teatro documentário, artivismo, biodrama, teatro-jornal, hipernaturalismo, performance, entre outras de difícil catalogação. Esse movimento, entretanto, não é sinônimo de abdicação ou de submissão aos imperativos da realidade bruta. Não é o atestado, inevitável, de falência da inteligibilidade e de refutação do sentido. Recusa de mediação (confundindo-se com primarismo fenomenológico) e irracionalismo não são fatalidades às quais o teatro contemporâneo estaria inexoravelmente submetido.

Este movimento em direção ao real não é exclusivo do teatro, já que corresponde a situações sociais gerais e ao espírito de uma época. Em entrevista sobre o cinema brasileiro dos anos 1990, Ismail Xavier mostra como nosso cinema, "empenhado na discussão do presente histórico", como afirma seu interlocutor, estaria às voltas com a questão da representabilidade:

Como falar do mundo depois de tanta saturação e desconfiança endereçadas às imagens, notadamente àquelas inseridas em códigos já conhecidos, domesticados? Há o sentimento de que elas trazem sempre uma dimensão ilusória, o que aconselha a inserção, no filme, de "salvaguardas": dar consciência do processo de produção, ensinar a ler as imagens, criar jogos duplos em que o próprio filme, como acontecimento, explicita sua forma de inserção num contexto que o ultrapassa e dentro do qual sua intervenção adquire sentido. (XAVIER, 2003, p.97)

Ismail Xavier destaca os impasses do cinema brasileiro contemporâneo lançando uma questão que cabe ao teatro: como falar do mundo de hoje? Além das aproximações entre o panorama cinematográfico e o teatral, um diagnóstico comum pode ser esboçado. Em ambas as modalidades artísticas houve um movimento de feições modernistas que tentou conciliar ruptura estética e crítica social. Xavier se refere especialmente ao Cinema Novo. Quanto ao campo teatral, a referência é à explosão teatral dos anos 1960 (Arena e Oficina à frente). A recusa do naturalismo (televisivo, hollywoodiano ou stanislavskiano), a autorreferencialidade e uma visão utópica, que combinava projeto nacional com a luta por outros modelos de arte e sociedade, formatavam várias das práticas artísticas que, nesta época, situavam-se no campo crítico. Passado o inverno da ditatura militar, a análise aponta, no âmbito do cinema, para a aceitação de imperativos de mercado (roteiros pré-formatados, culto das celebridades, happy 
end, achatamento das complexidades), a acomodação ao gosto médio do público, a "busca por diálogo" (outro nome para concessões temáticas e formais). Embora haja também a espaço para experiências menos integradas que, entre suas estratégias, buscam "as marcas do real" (XAVIER, 2003, p.101), isto é, a "mescla de material documentário e encenações" (XAVIER, 2000, p.103), mesmo quando continuam a conviver, de maneira mais ou menos pacífica, com a dramaturgia clássica norte-americana, que privilegia as subjetividades em detrimento da abordagem sócio-histórica. Eis a concepção que fundamenta as análises de Ismail Xavier:

Certo momento do capitalismo e da evolução da técnica que organiza a vida cotidiana engendra ou, pelo menos, favorece um estilo de representação que se mostra capaz de dar conta da experiência histórica; quando as coisas mudam, quando a ordem econômica e o aparato técnico vão dando cada vez menos sinais visíveis de sua lógica, é necessário outra forma de arte para falar desse mundo e de suas determinações, seu sentido, sua maneira de condicionar, moldar, excluir. (XAVIER, 2003, p.108)

Esta visão geral das relações entre arte e sociedade permite avançar no diagnóstico da emergência do real nas práticas artísticas contemporâneas. Para além da alegoria, tributária de estratégias ficcionais bem decodificadas, algumas propostas cinematográficas, na refutação dos códigos conhecidos e gastos da ficção, depararam-se com a irrupção do real na matéria da produção poética.

Filmes recentes de Eduardo Coutinho (especialmente Jogo de cena e Moscou) não apenas dialogam explicitamente com o teatro, como fazem do binômio realidade-ficção seu tema central. ${ }^{5}$ Dessas proposições artísticas fica a ideia de que o livre trânsito entre ficção, ensaio poético e filme documental clássico é uma das marcas definidoras do cinema brasileiro contemporâneo. ${ }^{6}$ Esse movimento não é inédito, na década de 1960 uma parte do cinema brasileiro já tinha vivido uma fase "aventurosa de experiências, quando encontrou novas formas de combinar ficção e documentação" (XAVIER, 2003, p.130). Essa avaliação mostra como o cinema recusou certas estruturas dramáticas, apoiadas na matriz melodramática, para responder ao

\footnotetext{
5 A riqueza do assunto sugere novas investigações, uma vez que o debate sobre "ficção e realidade" é recorrente, de maneira mais ou menos explícita, em grande quantidade de filmes: Vivre sa vie (Jean-Luc Godard, 1962), Oito e meio (Federico Fellini, 1963), A noite americana (François Truffaut, 1972), O filme de Nick (Wim Wenders, 1980), O estado das coisas (Wim Wenders, 1982), A rosa púrpura do Cairo (Woody Allen, 1985), The player (Robert Altman, 1992), Quero ser John Malkovich (Spike Jonze, 1999), Enquanto eu avançava... (Jonas Mekas, 2001), Mulholland drive (David Lynch, 2001), As praias de Agnès (Agnès Varda, 2007), Santiago (João Moreira Salles, 2007), Shirin (Abbas Kiarostami, 2008), O amor segundo B. Schianberg (Beto Brant, 2010).

6 Cf. por exemplo o texto de Luiz Zanin Oricchio, "Pré-estreia de Lula incendeia Brasília", Jornal O Estado de São Paulo, 17/11/2009, e o livro O cinema do real, organizado por Maria Dora Mourão e Amir Labaki, São Paulo, Cosac Naify, 2005.
} 
desafio "analítico" de iluminar a situação histórica e política do Brasil e da América Latina. Tanto o "drama doméstico burguês", que sobrevaloriza a experiência íntima e a "verdade interior", como outros esquemas narrativos tradicionais, vinculados ao naturalismo, impediam a execução do projeto crítico gestado na época.

É em função de uma crise ampla, que vai da mimese à ficção, passando pela personagem, pelo conflito intersubjetivo e pelo diálogo, que a crítica de teatro Barbara Engelhardt identifica um desejo de autenticidade no teatro contemporâneo: "Os diretores estão em busca daquilo que poderia ser uma 'credibilidade' no teatro [...] O teatro não quer mais fazer o jogo do teatro, por isso ele teatraliza o ato mesmo de interpretar" (ENGELHARDT, 2009, s/p). Esse tipo de teatro "trabalha de maneira permanente contra a ilusão de uma possível reconstrução da realidade pelo teatro. No lugar disso ele expõe a teatralidade da realidade, ou ao menos, daquilo que pode ser percebido como o 'mundo'” (ENGELHARDT, 2009, s/p).. A análise, ancorada na realidade alemã, sinaliza a opção por estratégias cênicas como o gosto do fragmento e da citação, a ironia, o artificialismo, a criação de um espaço-tempo antirealista, a utilização de novas tecnologias, o recurso a colagens de materiais considerados extra-teatrais, a criação de partituras coreográficas, todas elas afastadas da matriz dramática. Ao mesmo tempo embute a ideia de falência do projeto crítico ao admitir a impossibilidade da "reconstrução da realidade", o que equivale à aceitação da falta de sentido e da inteligibilidade vacilante, conclusão não generalizável para outras latitudes.

\section{Ideias fora do lugar}

Assim como as vanguardas das primeiras décadas do século 20 tentaram "direcionar a experiência estética (que se opõe à práxis vital), tal como o esteticismo a desenvolveu, para a vida cotidiana" (BÜRGER, 2008, p.77), parte do teatro contemporâneo tem buscado a presença (contra a representação), através da introdução do real/documental na obra artística. A submissão da ficção aos esquemas produtivos do capitalismo - simplificação da realidade, mistificação, banalização, excesso de pathos, vulgaridade, padronização, serialização, compartimentação, recuperação da rebeldia - tem relação com esse estado de coisas. A crítica da ficção responde ao fato dela ter funcionado, historicamente, como argamassa do teatro burguês. Para além dos temas que veicula, a forma ficção codificada no ocidente seria, ela mesma, portadora de valores. Esta não é a única hipótese explicativa para a emergência do real em cena. Há pelo menos duas opções: a situação expressa a busca de alternativas em função do esgotamento do teatro hegemônico 
(dramático, burguês, falsamente "desinteressado"); ou por outro lado, revela a enésima reacomodação do teatro dentro dos seus próprios limites.

Considerando a situação brasileira, o debate feito até agora ainda é lacunar. A "disparidade entre a sociedade brasileira, escravista, e as ideias do liberalismo europeu" (SCHWARZ, 2007, p.12) é o paradigma das "ideias fora do lugar", conforme a formulação de Roberto Schwarz. Esta situação histórica se consolida com a "cultura do favor" e persiste em desajustes e impropriedades relacionados às "relações de produção e parasitismo no país, [à] nossa dependência econômica e seu par, a hegemonia intelectual da Europa, revolucionada pelo Capital” (SCHWARZ, 2007, p.30). Porém, seguindo a argumentação de Schwarz, este deslocamento problemático das ideias abre um espaço de manobra que permite relações mais livres com a tradição popular, em geral menos codificadas. Parte da vitalidade do teatro brasileiro contemporâneo pode ser o resultado dessa peculiaridade nacional. Macaqueamos, sim, mas também exercitamos a crítica.

Faz sentido considerar, como Schwarz ao analisar a obra de Machado de Assis, que "nosso único estilo autêntico" é a frequentação "de todos os estilos". Esta "salada intelectual" vale para o teatro. "Tome-se neste sentido o belo estudo de Décio de A. Prado sobre João Caetano. No repertório do ator encontram-se peças neoclássicas, românticas e melodramas, e só não se encontra a maneira realista porque João Caetano a certa altura está velho para mudar" (SCHWARZ, 2007, p.146-147). Existe, então, um efeito de devoração de influências e modas (inaugurado com o bispo Sardinha), típico de culturas dependentes. O fato do Brasil estar "aquém da realidade" (SCHWARZ, 2007, p.11) a qual as teorias se referem (seria o caso da teoria do pós-dramático de Hans-Thies Lehmann), não é apenas motivo para o descarrilamento das teorias vindas da matriz, caso do Brasil colonial e imperial analisado por Schwarz. Isto é, os desconcertos, anacronismos e contradições entre teorias importadas e realidade local transformam, apenas parcialmente, nosso discurso em algo vazio e impróprio. A falsidade e o pastiche têm seu espaço, mas também seus limites, porque para além dos macaqueamentos e do "torcicolo cultural em que nos reconhecemos" (SCHWARZ, 2007, p.26) há uma força criativa, potencialmente rebelde e popular, que desafia a lapidação teórica europeia. O teatro contemporâneo brasileiro, dada nossa formação social e o papel que nos cabe na divisão internacional das tarefas capitalistas (produtor de matérias-primas, local privilegiado para a especulação financeira e a lavagem de dinheiro, fornecedor de mão-de-obra barata, reserva planetária de felicidade e sexo 
barato etc.), pode ter "uma ressonância profunda e afinada" caso "sinta, registre e desdobre - ou evite - o descentramento e a desafinação" (SCHWARZ, 2007, p.29). ${ }^{7}$

Teorias como a do teatro pós-dramático aplicadas automaticamente à realidade brasileira revelariam a desafinação de mais uma importação apressada. Sua crítica, em pensamento e ato, é o antídoto que desdobra ou evita o descentramento.

Parte do teatro contemporâneo, optando pelo real, refuta o drama em benefício da exposição imediata da realidade. São experiências que, problematizando ou negando a ficção, recorrem ao real e questionam pela raiz o regime da representação. As estratégias são múltiplas, podendo incluir a hiperexposição narcísica dos artistas e o recurso à confissão e ao depoimento; mas também podem incluir documentos que articulam críticas sistêmicas. A ideia de exposição "imediata", como se vê, não é isenta de problemas, porque admite, potencialmente, a aceitação new age (mas constantemente repaginada) do ritual, do subjetivismo, da vertigem das sensações, dos jogos formais, do discurso místico e circular, sempre em oposição ao projeto crítico, que por sua vez trabalha com a inteligibilidade e a busca do sentido. Para não caricaturar esta oposição é importante identificar as diferentes naturezas entre três crises: representação (mimesis) e fábula (mythos), por uma lado; sentido (logos), por outro.

O "questionamento da representação no teatro é testemunha de um questionamento global [...] A ideia que se impõe é que é preciso fazer o luto de toda representação de uma realidade explodida e caótica" (SAISON, 1998, p.37-38). É um risco ir tão longe; este luto significa abdicar da potencialidade do teatro em responder ao mundo. Seria afirmar que não damos conta da realidade, que nossas capacidades poéticas são insuficientes e ultrapassadas. Nesse modelo só haveria espaço para a distopia, solução compreensível no ambiente francês de final dos anos 1990, quando Saison formula sua tese, mas relativamente "fora do lugar" no Brasil dos nossos dias.

O trânsito entre ficção e realidade, a irrupção do real em cena e o questionamento radical do cosmos fictício dramático, fazem parte de novas práticas teatrais que muito pouco têm a ver com o modelo aristotélico. O que não significa que cedam ao canto de sereia das práticas performativas up to date. Portanto, ainda e sempre, cabe identificar o que há de mistificação na realidade social e nas práticas teatrais, incluindo aí a crítica da representação ficcional e o gosto pelo real. Não se trata, meramente, de constatar a existência de uma situação (ou crise) capaz de desmontar a represen-

7 Roberto Schwarz está se referindo à literatura brasileira, a transposição para o teatro é por nossa conta. 
tação teatral convencional, mas também de uma crise da representação teatral (que tem aspectos criativos e críticos) que pode, cenicamente (e não cinicamente), ajudar a entender e responder à crise social. As respostas não estão prontas porque dependem dos movimentos concretos que entrelaçam ação artística e dinâmica social.

\section{Referências bibliográficas}

COSTA, Iná Camargo. Sinta o drama. São Paulo: Vozes, 1998.

BENJAMIN, Walter. A obra de arte na era de sua reprodutibilidade técnica. Trad. Sergio Paulo Rouanet. In Magia e técnica, arte e política. Obras escolhidas I, São Paulo: Brasiliense, 1985.

BRECHT, Bertolt. Écrits sur le théâtre, v. 2. Trad. Jean Tailleur e Edith Winkler. Paris: Arche, 1979.

BÜRGER, Peter. Teoria da vanguarda. Trad. José Pedro Antunes. São Paulo: Cosac Naify, 2008.

ENGELHARDT, Barbara, Le théâtre allemand contre l'illusion. Mouvement.net, $\mathrm{n}^{\circ} 29$ julho/agosto, 2004. Disponível em <http://www.artishoc.com/site.php?rub=5\&fiche_mut_ id=\&fiche_alias=mouvement\&id=7165\&\&mode_view=lecture $>$. (Acesso em 15 out. 2013)

FOSTER, Hal. El retorno de lo real. Trad. Alfredo Brotons Muñoz. Madri: Akal, 2001.

LABAKI, Amir; MOURÃO, Dora (orgs.). O cinema do real. São Paulo: Cosac Naify, 2005.

LEHMANN, Hans-Thies. Teatro pós-dramático. Trad. Pedro Süssekind. São Paulo: Cosac Naify, 2007.

ORICCHIO, Luiz Zanin. Pré-estreia de Lula incendeia Brasília. Jornal O Estado de São Paulo, 17/11/2009.

Liberdade, 2003.

Cinema de novo. Um balanço crítico da retomada. São Paulo: Estação

SAISON, Maryvonne. Les théâtres du réel. Paris: L'Harmattan, 1998.

SARRAZAC, Jean-Pierre. Du détour et de la variété des détours In Écritures dramatiques contemporaines (1980-2000). L'avenir d'une crise. Études théâtrales, n 24-25, Centre d'études théâtrales, Universidade Católica de Louvain e Instituto de Estudos teatrais, Paris 3, 2002, pp. 77-87.

SCHWARZ, Roberto. Ao vencedor as batatas. São Paulo: Duas Cidades, Editora 34, 2007. Boitempo, 2008.

Valor intelectual. In Crítica à razão dualista, O ornitorrinco. São Paulo:

SZONDI, Peter. Teoria do drama moderno:(1880-1950). Editora Cosac Naify, 2003.

XAVIER, Ismail. O olhar e a cena. São Paulo: Cosac Naify, 2003.

2000, pp. 97-138.

O cinema brasileiro dos anos 90 (entrevista). In Praga, nº 9. São Paulo: Hucitec,

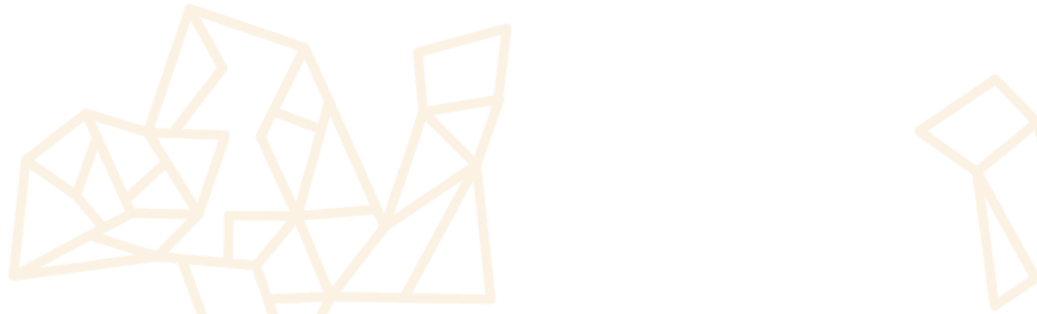

